\title{
Short Term Methylphenidate Treatment Does Not Increase Myocardial Injury in the Ischemic Rat Heart
}

\author{
Sarah L. SEELEY ${ }^{1}$, Manoranjan S. D'SOUZA ${ }^{1}$, Thorne S. STOOPS ${ }^{1}$, \\ Boyd R. RORABAUGH ${ }^{2}$
}

${ }^{1}$ Ohio Northern University School of Pharmacy, Ada, OH, USA, ${ }^{2}$ Marshall University School of Pharmacy, Huntington, WV, USA

Received November 11, 2019

Accepted March 10, 2020

Epub Ahead of Print May 29, 2020

\section{Summary}

Methylphenidate is commonly used for the treatment of attention deficit hyperactivity disorder. The cardiovascular safety of methylphenidate has been a subject of debate with some studies indicating that methylphenidate increases the likelihood of experiencing a myocardial infarction. However, it is unknown whether methylphenidate worsens the extent of injury during an ischemic insult. The purpose of this study was to determine whether short term exposure to methylphenidate increases the extent of myocardial injury during an ischemic insult. Male and female rats received methylphenidate $(5 \mathrm{mg} / \mathrm{kg} /$ day $)$ or saline for 10 days by oral gavage. Hearts were subjected to $20 \mathrm{~min}$ of ischemia and $2 \mathrm{~h}$ of reperfusion on a Langendorff isolated heart apparatus on day 11. Cardiac contractile function was monitored via an intraventricular balloon and myocardial injury was assessed by triphenyltetrazolium chloride staining. Methylphenidate significantly increased locomotor activity in male and female rats, confirming absorption of this psychostimulant into the central nervous system. Male hearts had significantly larger infarcts than female hearts, but methylphenidate had no impact on infarct size or postischemic recovery of contractile function in hearts of either sex. These data indicate that methylphenidate does not increase the extent of injury induced by an ischemic insult.

\section{Key words}

Myocardial ischemia • Methylphenidate • Heart attack • Attention deficit hyperactivity disorder

\section{Corresponding author}

B. R. Rorabaugh, Marshall University School of Pharmacy, 1 John
Marshall Drive, Huntington, WV 25755, USA. E-mail: rorabaughb@marshall.edu

\section{Introduction}

Methylphenidate is commonly used for the treatment of attention deficit hyperactivity disorder and narcolepsy. Prescriptions for 18.6 million tons of methylphenidate were filled in the United States in 2016 (Piper et al. 2018). The cardiovascular safety of methylphenidate has been a topic of debate. Some reports suggest that methylphenidate increases the likelihood of experiencing a heart attack (Thompson and Thompson 2010, Munk et al. 2015, Shin et al. 2016), while other studies indicate that methylphenidate does not significantly increase this risk (Schultz et al. 1998, Antel et al. 2015, Liu et al. 2019). Package inserts for methylphenidate include warnings that patients have experienced myocardial infarctions while using this drug at prescribed dosages. Previous clinical studies regarding the impact of methylphenidate on the heart have assessed the cardiac risk of this drug in terms of whether methylphenidate increases the likelihood of experiencing a heart attack (Antel et al. 2015, Shin et al. 2016). In contrast, we are not aware of any studies that have assessed whether or not methylphenidate alters the extent of myocardial injury when an ischemic insult occurs.

Previous work in our laboratory demonstrated that female rats (but not their male siblings) that are repeatedly exposed to methamphetamine over a 10 day period develop myocardial hypersensitivity to ischemic injury 
(Rorabaugh et al. 2017c). This is evidenced by increased infarct sizes and attenuation of postischemic recovery of contractile function in hearts of methamphetamine-treated rats. Importantly, this effect persists following at least a month of subsequent abstinence from methamphetamine, indicating that this psychostimulant induces long lasting cardiac effects that persist after use of the drug has been discontinued (Rorabaugh et al. 2017c). We have also reported that female rats (but not their male siblings) that were prenatally exposed to methamphetamine become hypersensitive to ischemic injury as adults (Rorabaugh et al. 2016). This is consistent with previous work demonstrating that prenatal exposure to methamphetamine causes behavioral and neurological deficits in adult offspring (Hrebickova et al. 2016, Holubova et al. 2017, Dong et al. 2018, Slamberova 2019). Methylphenidate and methamphetamine both increase dopaminergic and adrenergic signaling, but they differ with respect to their mechanisms of action. Methamphetamine actively promotes the release of these neurotransmitters from intracellular storage vesicles by reversing the direction of their transport through NET and DAT (Han and Gu 2006). Methylphenidate does not induce the release of norepinephrine and dopamine (Luethi et al. 2018). Rather, methylphenidate act as a competitive antagonist of NET and DAT and prevents the reuptake of norepinephrine and dopamine after they have been released. In contrast to methamphetamine, it is unknown whether methylphenidate treatment increases the extent of myocardial injury during an ischemic insult. The purpose of the present study was to determine whether methylphenidate hypersensitizes the heart to ischemic injury. We hypothesized that methylphenidate would worsen the extent of myocardial injury in the ischemic heart in a manner similar to that of methamphetamine.

\section{Methods}

Animals

Sprague Dawley rats used for this study were obtained from a breeding colony maintained at Ohio Northern University. The colony originated from rats purchased from Charles River Laboratories (Boston, MA) Strain Code 001. Rats were pair housed in standard Plexiglas cages with free access to food and water and were maintained on a reversed $12 \mathrm{~h} / 12 \mathrm{~h}$ light/dark schedule (lights off at 07:00 to 19:00). Administration of methylphenidate for the treatment of attention deficit hyperactivity disorder in humans is typically limited to the waking hours because this psychostimulant interferes with sleep when administered at night. Thus, rats were maintained on a reversed light cycle in this study to facilitate the administration of methylphenidate during the "active" (dark) phase of the rodent diurnal cycle to better mimic clinical use of the drug. All procedures were approved by the Institutional Animal Care and Use Committee of Ohio Northern University and were conducted in compliance with the National Institutes of Health Guide for the Care and Use of Laboratory Animals.

\section{Subchronic treatment of rats with methylphenidate}

A total of 47 male and female rats ( 8 weeks of age) were randomly assigned to methylphenidate (11 male; 13 female) or saline (11 male; 12 female) treatment groups. The animals received a single daily dose of a racemic mixture of d-threo- and 1-threomethylphenidate $(5 \mathrm{mg} / \mathrm{kg} /$ day $)$ or saline by oral gavage at 10:00 am for 10 consecutive days. Previous work indicating that oral administration of this dose produces plasma methylphenidate concentrations within the clinically therapeutic range (Gerasimov et al. 2000, Montagnini et al. 2014). Hearts were isolated on day 11 ( $24 \mathrm{~h}$ after the last dose), mounted on a Langendorff isolated heart apparatus, and subjected to an ischemic insult as described below. Methylphenidate was purchased from Spectrum Chemical Manufacturing Corporation (New Brunswick, NJ, USA).

\section{Spontaneous locomotor activity}

Locomotor activity was measured using a threechannel Opto-M4 Auto-Track System (Columbus Instruments, Columbus, $\mathrm{OH}$ ) located in a dark room illuminated by a red $60 \mathrm{~W}$ light bulb as previously described (Rorabaugh et al. 2016, Rorabaugh et al. 2017a). Each rat was individually placed in the open field immediately after administration of methylphenidate on day 1 and day 10. Locomotor activity (determined by the total number of photo beam breaks) was monitored for $1 \mathrm{~h}$. The total number of photobeam breaks was automatically converted into distance travelled $(\mathrm{cm})$ by the Opto-M4 software that controls the apparatus.

\section{Langendorff isolated heart experiments}

The Langendorff isolated heart model was used to assess the impact of subchronic methylphenidate treatment on myocardial sensitivity to ischemic injury. Rats were anesthetized with sodium pentobarbital 
(100 mg/kg i.p.), and their hearts were rapidly removed and mounted on a Langendorff isolated heart apparatus. Krebs solution (in mM: $118 \mathrm{NaCl}, 4.7 \mathrm{KCl}, 1.2 \mathrm{MgSO}_{4}$, $25 \mathrm{NaHCO}_{3}, 1.2 \mathrm{KH}_{2} \mathrm{PO}_{4}, 0.5 \mathrm{Na}_{2}$ EDTA, 11 glucose, and $2.5 \mathrm{CaCl}_{2}$, pH 7.4) was perfused through an aortic cannula at a constant pressure of $80 \mathrm{~mm} \mathrm{Hg}$. Contractile function of the left ventricle was measured using an intraventricular balloon connected to a pressure transducer and Powerlab 4SP data acquisition system (AD Instruments, Colorado Springs, CO) as previously described (Rorabaugh et al. 2016, Rorabaugh et al. 2017c). Hearts were equilibrated for $25 \mathrm{~min}$ prior to the onset of $20 \mathrm{~min}$ global ischemia (induced by terminating the flow of Krebs solution) and $2 \mathrm{~h}$ of reperfusion. Preischemic contractile function was measured immediately prior to ischemia, and postischemic recovery of contractile function was measured following $10 \mathrm{~min}$, $20 \mathrm{~min}, 40 \mathrm{~min}$, and $1 \mathrm{~h}$ of reperfusion. Coronary flow rate was measured by quantifying the volume of perfusate collected over a $30 \mathrm{~s}$ time period immediately prior to the onset of ischemia and during a $30 \mathrm{~s}$ time period following $1 \mathrm{~h}$ of reperfusion. Hearts were perfused for an additional hour ( $2 \mathrm{~h}$ of total reperfusion) prior to triphenyltetrazolium chloride (TTC) staining. Infarct sizes of TTC stained hearts were measured by an investigator who was blinded to the drug treatment and sex of each animal using NIH Image J software as previously described (Rorabaugh et al. 2016, Rorabaugh et al. 2017c).

\section{Statistical analysis}

Infarct sizes were compared by two-way ANOVA and Bonferoni's post hoc analysis using sex (male vs. female) and drug treatment (methylphenidate vs saline) as factors. Parameters of cardiac function (developed pressure, $+\mathrm{dP} / \mathrm{dT}$, $-\mathrm{dp} / \mathrm{dT}$, heart rate, and end diastolic pressure, and coronary flow rate) were analyzed by three-way ANOVA and Bonferonni's post hoc analysis with sex, drug treatment, and time as factors. Time (preischemic contractile function and $10 \mathrm{~min}$, $20 \mathrm{~min}$, $40 \mathrm{~min}$, and $60 \mathrm{~min}$ postischemic recovery of contractile function) was analyzed as a repeated measure. Locomotor activity data were analyzed by two-way ANOVA with time (day 1 and day $10=$ repeated measure) and drug treatment as factors. All data analyses were performed using Graphpad Prism software (Graphpad Inc., San Diego, CA). Hearts from 2 methylphenidate-treated rats (one male and one female) were omitted from infarct size analyses because of a technical error that occurred during the TTC staining procedure. However, all other data from these animals (locomotor activity and parameters of contractile function) were retained.

\section{Results}

\section{Body weight and heart weight}

Starting body weight, weight gain over the 10 day treatment period, and heart weight were greater in male rats than in female rats (Table 1). However, methylphenidate had no impact on these parameters in animals of either sex. Heart weight/body weight ratio was unaffected by methylphenidate (Table 1).

\section{Methylphenidate increases locomotor activity in male} and female rats

Locomotor activity was measured to verify that the orally administered methylphenidate was being absorbed and producing a centrally mediated response. Two-way ANOVA indicated significant overall effects of methylphenidate treatment in both male $\left[\mathrm{F}=21_{(1,20)}\right.$,

Table 1. Body weight, weight gain, and heart weight following saline or methylphenidate treatment.

\begin{tabular}{lcccc}
\hline & Male Saline & $\begin{array}{c}\text { Male } \\
\text { Methylphenidate }\end{array}$ & Female Saline & $\begin{array}{c}\text { Female } \\
\text { Methylphenidate }\end{array}$ \\
\hline Starting body weight $(g)$ & $387 \pm 13$ & $393 \pm 14$ & $226 \pm 6^{\mathrm{a}}$ & $232 \pm 5^{\mathrm{b}}$ \\
Weight gain $(\mathrm{g})$ & $55 \pm 3$ & $58 \pm 7$ & $5 \pm 2^{\mathrm{a}}$ & $8 \pm 3^{\mathrm{b}}$ \\
Heart weight $(\mathrm{mg})$ & $1085 \pm 52$ & $1198 \pm 56$ & $709 \pm 20^{\mathrm{a}}$ & $759 \pm 21^{\mathrm{b}}$ \\
Heart weight/Body & $2.8 \pm 0.1$ & $3.1 \pm 0.1$ & $3.2 \pm 0.1$ & $3.2 \pm 0.1$ \\
weight ratio (mg/g) & & & & \\
\hline
\end{tabular}

Two-way ANOVA indicated significant effects of sex on starting body weight $\left[F=252_{(1,42),} p<0.0001\right]$, weight gain $\left[F=157_{(1,41) \text {, }}\right.$ $\mathrm{p}<0.0001]$, heart weight $\left[\mathrm{F}=252_{(1,42),} \mathrm{p}<0.001\right]$, and heart weight / body weight ratio $\left[\mathrm{F}=7.7_{(1,41)}, \mathrm{p}<0.01\right]$. However, methylphenidate had no significant effect on these parameters. ${ }^{\mathbf{a}}$ indicates a significant difference compared to saline-treated male rats. ${ }^{\mathbf{b}}$ indicates a significant difference $(p<0.0001)$ compared to methylphenidate-treated male rats. 
$\mathrm{p}<0.0005]$ and female $\left[\mathrm{F}=15_{(1,23)}, \mathrm{p}<0.001\right]$ rats (Fig. 1). Bonferonni's post hoc analysis indicated that methylphenidate significantly increased locomotor activity in animals of both sexes and that this effect was not diminished with repeated exposure to the drug over the course of the 10-day treatment.
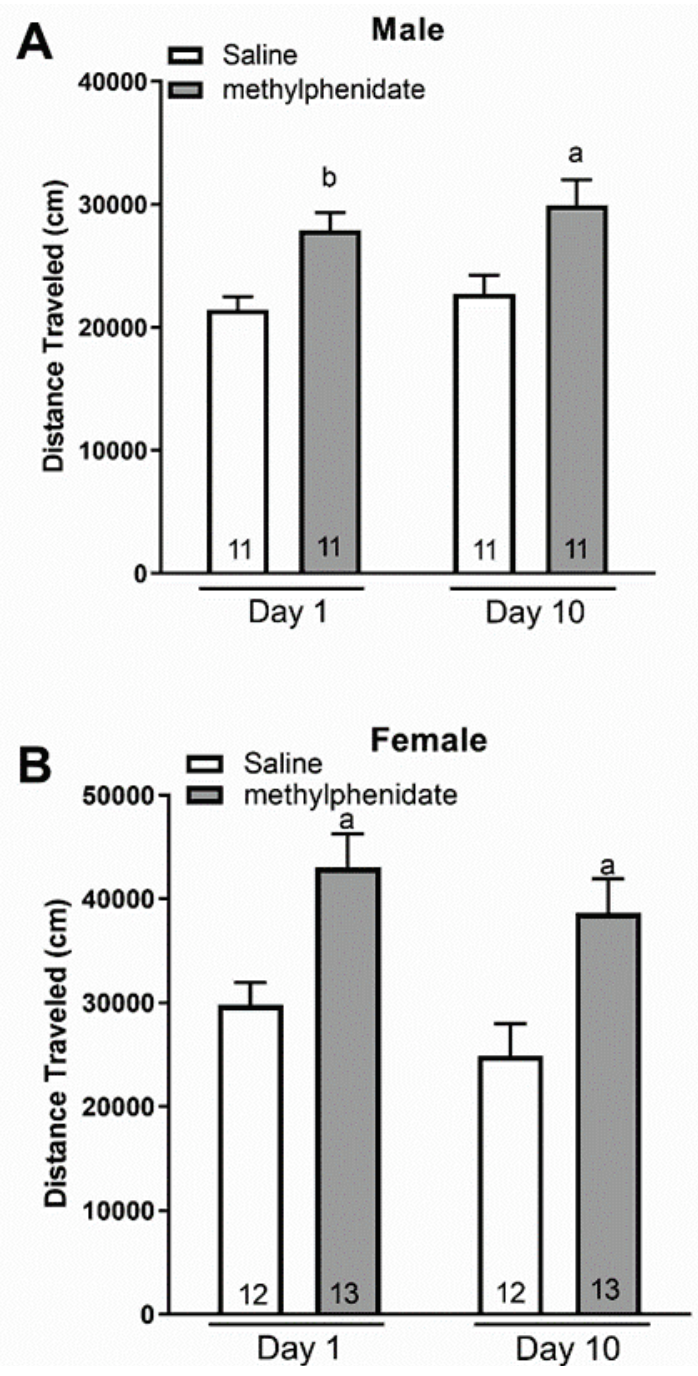

Fig. 1. Methylphenidate increases locomotor activity in male and female rats after both acute and repeated administration. Male (A) and female (B) rats were treated with saline or methylphenidate $(5 \mathrm{mg} / \mathrm{kg})$ by oral gavage for 10 consecutive days. Locomotor activity was measured for $1 \mathrm{~h}$ immediately after the first (day 1) and last (day 10) drug treatment. Methylphenidate significantly increased locomotor activity of both male and female rats on day 1 and day 10. Data represent the mean \pm SEM of $11-13$ rats. ${ }^{a}$ indicates $p<0.001$. ${ }^{b}$ indicates $p<0.05$.

\section{Preischemic contractile function}

Hearts were isolated and mounted on a Langendorff isolated heart apparatus $24 \mathrm{~h}$ after the final methylphenidate or saline gavage (day 11). Ten days of methylphenidate treatment had no significant impact on preischemic parameters of contractile function (Fig. 2A-E) or coronary flow rate (Fig. 2F) in hearts isolated from either male or female rats.

\section{Postischemic recovery of contractile function and infarct size}

Two-way ANOVA indicated that female hearts had significantly $\left[\mathrm{F}=5.4_{(1,40)}, \mathrm{p}<0.05\right]$ smaller infarcts than hearts from male rats (Fig. 3) following exposure to a $20 \mathrm{~min}$ ischemic insult. This is consistent with previous work from our laboratory (Rorabaugh et al. 2016, Rorabaugh et al. 2017c) and the work of others (Brown et al. 2005, Johnson et al. 2006). Methylphenidate had no effect on infarct size $\left[\mathrm{F}=1.9_{(1,40)}, \mathrm{p}=0.18\right]$ in hearts of either sex (Fig. 3).

Three way ANOVA indicated significant effects of time (before ischemia vs postischemic recovery) on developed pressure $\left[\mathrm{F}=78_{(3,64),} \mathrm{p}<0.0001\right], \quad+\mathrm{dP} / \mathrm{dT}$ $\left[\mathrm{F}=152_{(3,98)}, \mathrm{p}<0.0001\right],-\mathrm{dP} / \mathrm{dT} \quad\left[\mathrm{F}=153_{(3,121)}, \mathrm{p}<0.0001\right]$, heart rate $\left[\mathrm{F}=152_{(3,98)}, \mathrm{p}<0.001\right]$, end diastolic pressure $\left[\mathrm{F}=203_{(1,43)}, \quad \mathrm{p}<0.0001\right]$, and flow rate $\left[\mathrm{F}=138_{(1,43)}\right.$, $\mathrm{p}<0.0001]$. This reflects the fact that cardiac contraction stopped during the $20 \mathrm{~min}$ period of ischemia and did not return to the preischemic level of contractility during the recovery period. There was also a significant interaction between time and drug treatment with respect to $+\mathrm{dP} / \mathrm{dT}$ $\left[\mathrm{F}=5.6_{(6,23)}, \quad \mathrm{p}<0.01\right], \quad-\mathrm{dP} / \mathrm{dT} \quad\left[\mathrm{F}=3.0_{(6,249)}, \mathrm{p}<0.01\right]$, and heart rate $\left[\mathrm{F}=2.3_{(6,253)}, \mathrm{p}<0.05\right]$. However, methylphenidate had no effect on parameters of preischemic contractile function or postischemic recovery of contractile function in either male or female hearts at any time point before or after ischemia (Fig. 2). Heart rate was nominally (but not significantly) depressed in male rats at the end of the reperfusion period (Fig. 1B). This reflects the fact that 5 male hearts ( 2 from saline treated rats and 3 methylphenidate treated rats) did not recover a stable level of contractile function during the recovery period. These 5 hearts either contracted intermittently or did not contract at all and were assigned values of " 0 " for heart rate and other postischemic contractile parameters. Only 1 female heart (from a saline-treated animal) failed to recovery any postischemic contractile function.

\section{Discussion}

Prior studies assessing the cardiac risk associated with using methylphenidate for the treatment of ADHD have focused on determining whether or not methylphenidate increases the likelihood of experiencing a myocardial infarction. Some clinical studies have 
A

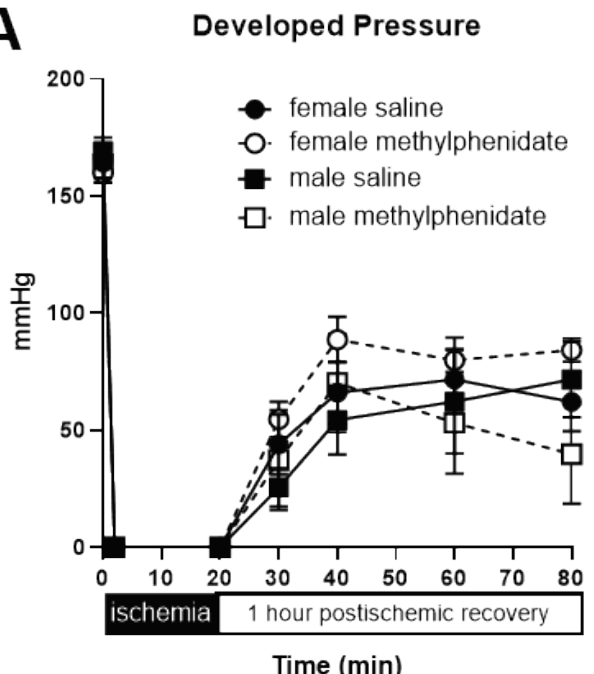

C
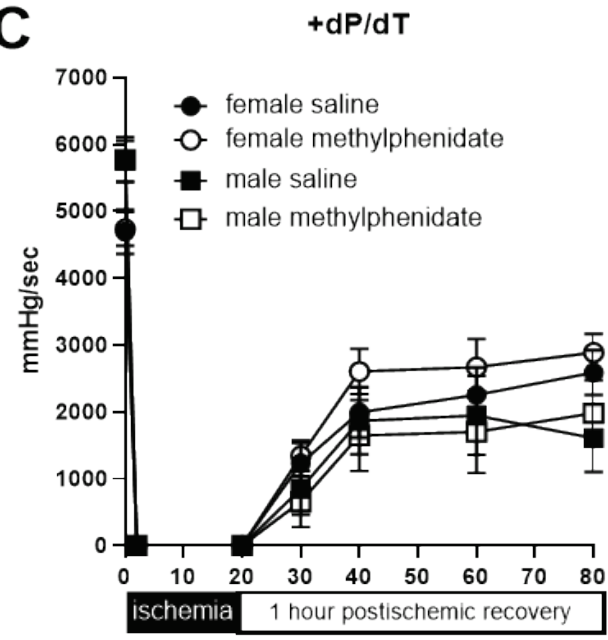

E

Time (min)

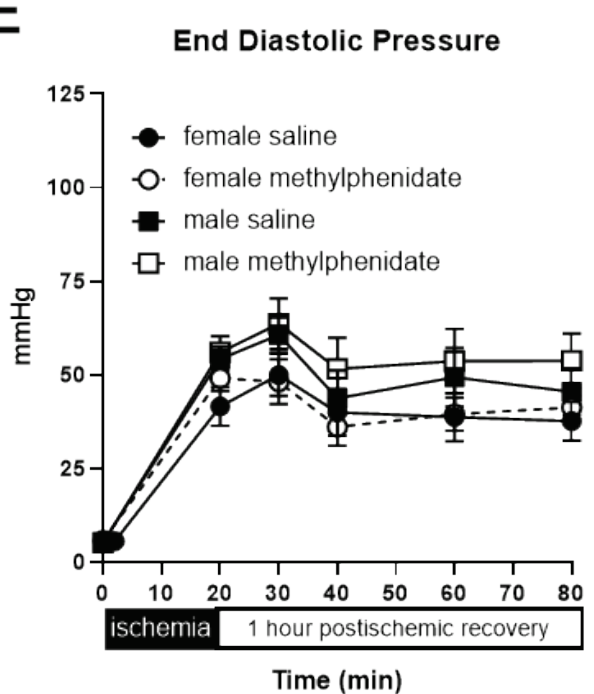

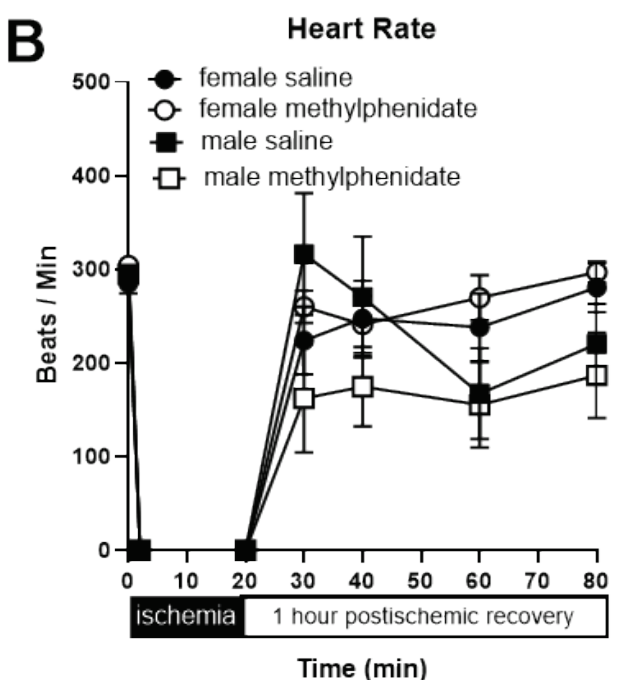

D

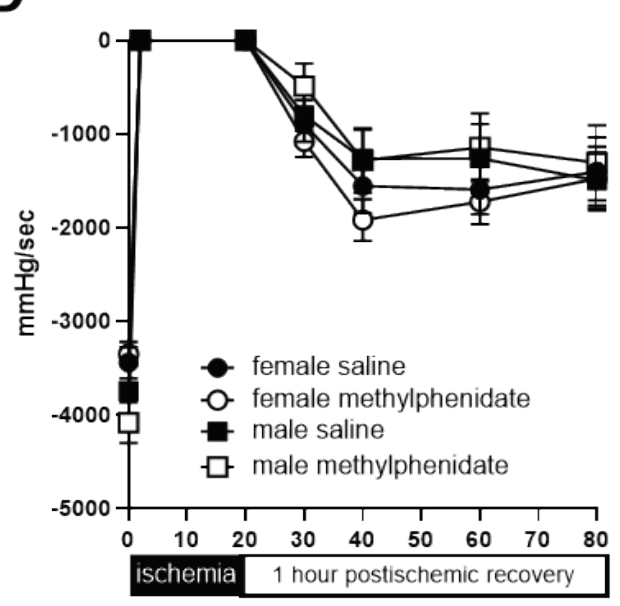

F Time (min)

\section{Coronary Flow Rate}

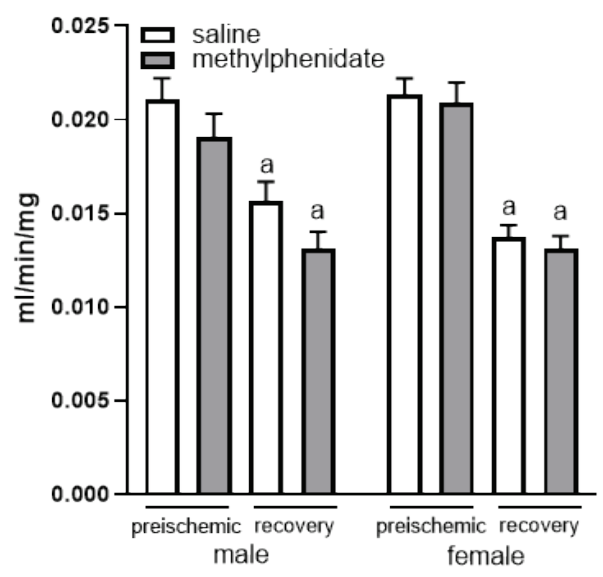

Fig. 2. Repeated methylphenidate administration for 10 days has no effect on preischemic contractile function or postischemic recovery of contractile function. Three way ANOVA indicated significant effects of time (before ischemia vs postischemic recovery) on developed pressure $\left[F=78_{(3,64),} p<0.0001\right](\mathbf{A})$, heart rate $\left[F=152_{(3,98),} p<0.001\right](\mathbf{B}),+d P / d T\left[F=152_{(3,98),} p<0.0001\right](\mathbf{C}),-d P / d T\left[F=153_{(3,121)}\right.$, $\mathrm{p}<0.0001]$ (D), end diastolic pressure $\left[F=203_{(1,43)}, p<0.0001\right](\mathbf{E})$, and flow rate $\left[F=138_{(1,43),} p<0.0001\right](\mathbf{F})$. There was also a significant interaction between time and drug treatment with respect to heart rate $\left[F=2.3_{(6,253),} p<0.05\right](B),+d P / d T\left[F=5.6_{(6,239) \text {, }}\right.$ $\mathrm{p}<0.01](\mathbf{C})$, and $-\mathrm{dP} / \mathrm{dT}\left[\mathrm{F}=3.0_{(6,249)}, \mathrm{p}<0.01\right](\mathbf{D})$. However, methylphenidate had no effect on parameters of preischemic contractile function or postischemic recovery of contractile function in either male or female hearts. 


\section{Infarct Size}
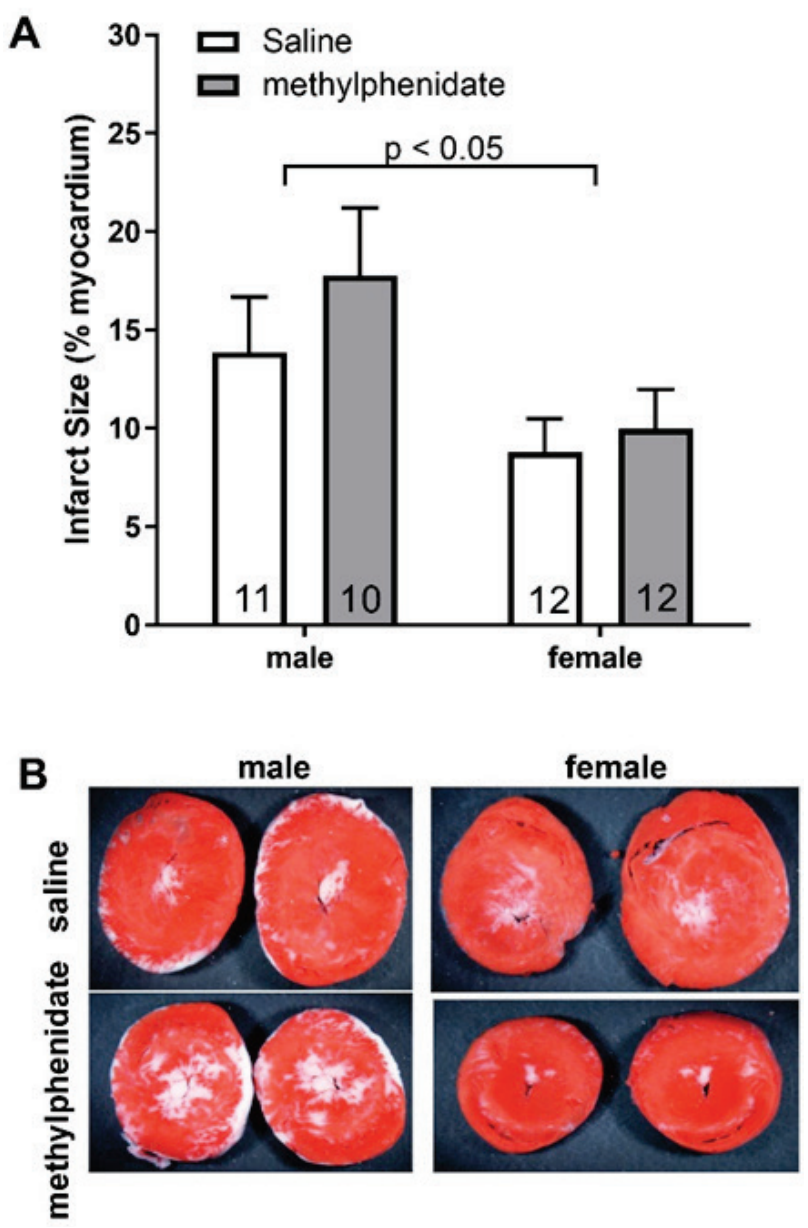

Fig. 3. Repeated administration of methylphenidate for 10 days does not hypersensitize the heart to ischemic injury. Male and female rats were treated with saline or methylphenidate $(5 \mathrm{mg} / \mathrm{kg})$ by oral gavage for 10 consecutive days. Isolated hearts were subjected to a $20 \mathrm{~min}$ ischemic insult on day 11 . Infarct sizes were measured by triphenyltetrazolium chloride staining. Infarcts were significantly larger in male hearts compared to female hearts $\left[F=5.4_{(1,40)}, p<0.05\right]$. However, methylphenidate had no effect on infarct size. Data in panel $(\mathbf{A})$ represent the mean \pm standard deviation of hearts from 10-12 rats. Photographs of representative tissue slices from stained hearts are shown in panel (B).

concluded that methylphenidate produces little or no increased cardiovascular risk (Antel et al. 2015, Liu et al. 2019) while other reports indicate that methylphenidate may increase the risk of experiencing a heart attack (Thompson and Thompson 2010, Munk et al. 2015, Shin et al. 2016). The present study differs from previous work because we did not assess the impact of methylphenidate on the likelihood of experiencing a myocardial infarction. Rather we assessed whether or not methylphenidate alters the extent of myocardial injury that develops when an ischemic insult occurs. Our finding that methylphenidate does not worsen the extent of myocardial injury in hearts subjected to ischemia may provide an additional level of confidence in the cardiac safety of this commonly prescribed psychostimulant.

The observation that infarct sizes in female hearts were significantly smaller than those of male hearts (Fig. 2) is consistent with prior work from our own lab and the work of others (Johnson et al. 2006, Rorabaugh et al. 2016, Rorabaugh et al. 2017b). Resistance of the female heart to ischemic injury has been attributed to sex differences in cardioprotective signaling pathways involving ATP-dependent potassium channels (Johnson et al. 2006), nitric oxide (Shao et al. 2016), the mitochondrial permeability transition pore (Milerova et al. 2016), and to the cardioprotective effect of estrogen (Ma et al. 2009, Wang et al. 2010). Our previous work demonstrated that methamphetamine exposure during either the prenatal period (Rorabaugh et al. 2016) or during early adulthood (Rorabaugh et al. 2017c) negates the cardioprotective benefit of being female. In contrast, the current data indicate that methylphenidate does not interfere with the endogenous cardioprotective mechanisms of the female heart.

Methylphenidate and methamphetamine both increase adrenergic and dopaminergic signaling, but only methamphetamine causes the heart to become hypersensitive to ischemic injury (Rorabaugh et al. 2017c). Our previous study (Rorabaugh et al. 2017c) demonstrated that subcutaneous injection of methamphetamine ( $5 \mathrm{mg} / \mathrm{kg}$ for 10 days) caused hearts of female rats (but not their male littermates) to become hypersensitive to ischemic injury as evidenced by increased infarct size and attenuated postischemic recovery of contractile function (Rorabaugh et al. 2017c). Methylphenidate ( $5 \mathrm{mg} / \mathrm{kg}$ for 10 days) was administered orally in the present study to mimic the clinical route of administration of this drug. Repeating these experiments with subcutaneously administered methylphenidate $(5 \mathrm{mg} / \mathrm{kg}$ for 10 days) produced similar results (data not shown), indicating that the route of administration does not account for the observed differences in the impact of these psychostimulants on the ischemic heart. Methamphetamine and methylphenidate both produce pharmacological effects that are mediated through the central nervous system (CNS). However, studies with isolated cardiomyocytes provide evidence that methamphetamine also has direct effects on cardiomyocytes that are independent of the CNS. Methamphetamine has been reported to stimulate apoptosis (Leung et al. 2014), hypertrophy (Maeno et al. 
2000), reorganization of myofibrils (Maeno et al. 2000) and enhances the activity of L type calcium channels (Sugimoto et al. 2009) in isolated cardiomyocytes that are separated from autonomic influence. We do not know whether the previously observed effects of methamphetamine on the ischemic heart (Rorabaugh et al. 2017c) is mediated through the CNS or if it resulted from a direct action of methamphetamine on the heart independent of the CNS. It is also unknown whether methylphenidate can act directly (independent of the CNS) on cardiomyocytes to induce the same changes that have been reported for methamphetamine. These gaps in our knowledge of the cardiac effects of methylphenidate make it difficult to determine why methylphenidate does not have the same detrimental impact on the ischemic heart that occurs following exposure to methamphetamine (Rorabaugh et al. 2017c).

The half-life of methylphenidate is less than $3 \mathrm{~h}$ in humans (Wong et al. 1998). Consequently, it is often administered twice/day or administered as a long acting formulation to achieve more prolonged therapeutic efficacy in the treatment of ADHD. In addition, methylphenidate use typically follows a chronic (years) time course. The 10 day treatment protocol used in this study was based on prior work demonstrating that 10 days of methamphetamine treatment hypersensitizes the heart (Rorabaugh et al. 2017c) and brain (Zuloaga et al. 2016) to injury caused by a subsequent ischemic insult. We cannot rule out the possibility that methylphenidate may worsen ischemic injury if administered multiple times/day, as a long acting formulation, or for a more chronic duration. However, our data provide evidence that short term exposure (10 days) does not hypersensitize the heart to ischemic injury.

Although methylphenidate is most commonly associated with the treatment of children with ADHD, there is growing evidence that this psychostimulant may be useful for the treatment of geriatric depression (Lavretsky et al. 2003, Lavretsky et al. 2015, Patel et al. 2017) and cognitive function in elderly patients with Alzheimer's disease (Rosenberg et al. 2013, Padala et al. 2018). A recent study of the French General Health Insurance Database indicated that $34 \%$ of new methylphenidate users in France are adults (Pauly et al. 2018). Ischemic heart disease primarily impacts the elderly population, but the animals used in this study were young adults ( 8 weeks). Further work is needed to determine whether long term methylphenidate use alters the cardiac response to an ischemic insult or increases the likelihood of an adverse cardiovascular event in the geriatric population.

The hearts in the present study exhibited relatively low levels of postischemic recovery of contractile function relative to their small infarct sizes, suggesting that the postischemic recovery may have been attenuated by stunning rather than by extensive tissue death. Our data indicate that methylphenidate had no impact on postischemic recovery of contractile function during the first hour of reperfusion. However, we do not know how methylphenidate may have impacted postischemic recovery over a longer time course. The inability of the Langendorff isolated heart model to measure long-term recovery of myocardial contractile function following an ischemic insult is a limitation of this experimental model. Another limitation of this work is the use of a relatively short period of ischemia (20 min). We cannot exclude the possibility that methylphenidate may have negatively impacted infarct size if a longer period of ischemia (resulting in more severe myocardial injury) had been utilized. Finally, methylphenidate is typically prescribed for a chronic time period. Our data provide evidence that short-term (10 days) methylphenidate treatment does not worsen myocardial ischemic injury, but we do not know if there is a detrimental cardiac effect on the ischemic heart following more chronic exposure.

In summary, prior studies investigating the impact of methylphenidate on the ischemic heart have focused on assessing whether or not methylphenidate increases the likelihood of experiencing a myocardial infarction. These studies have produced mixed results. Some investigators have reported that methylphenidate increases the likelihood of experiencing a heart attack (Thompson and Thompson 2010, Munk et al. 2015, Shin et al. 2016), while others have concluded that methylphenidate does not significantly increase this risk (Schultz et al. 1998, Antel et al. 2015, Liu et al. 2019). This is the only study that we are aware of to measure the extent of myocardial injury in the ischemic heart following a period of methylphenidate exposure. Caution is warranted regarding the use of this psychostimulant in patients who already have risk factors for cardiovascular disease. However, our data suggest that short term use of methylphenidate does not worsen the extent of myocardial injury that occurs during an ischemic insult. 


\section{Conflict of Interest}

There is no conflict of interest.

\section{Acknowledgements}

This work was supported by a grant from the National Heart Lung Blood Institute (7R15HL145546-02) to BRR.

\section{References}

ANTEL J, ALBAYRAK O, HEUSCH G, BANASCHEWSKI T, HEBEBRAND J: Assessment of potential cardiovascular risks of methylphenidate in comparison with sibutramine: do we need a SCOUT (trial)? Eur Arch Psychiatry Clin Neurosci 265: 233-247, 2015. https://doi.org/10.1007/s00406-014-0522-8

BROWN DA, LYNCH JM, ARMSTRONG CJ, CARUSO NM, EHLERS LB, JOHNSON MS, MOORE RL: Susceptibility of the heart to ischaemia-reperfusion injury and exercise-induced cardioprotection are sex-dependent in the rat. J Physiol 564: 619-630, 2005. https://doi.org/10.1113/jphysiol.2004.081323

DONG N, ZHU J, HAN W, WANG S, YAN Z, MA D, GOH ELK, CHEN T: Maternal methamphetamine exposure causes cognitive impairment and alteration of neurodevelopment-related genes in adult offspring mice. Neuropharmacology 140: 25-34, 2018. https://doi.org/10.1016/j.neuropharm.2018.07.024

GERASIMOV MR, FRANCESCHI M, VOLKOW ND, GIFFORD A, GATLEY SJ, MARSTELLER D, MOLINA PE, DEWEY SL: Comparison between intraperitoneal and oral methylphenidate administration: A microdialysis and locomotor activity study. J Pharmacol Exp Ther 295: 51-57, 2000.

HAN DD, GU HH: Comparison of the monoamine transporters from human and mouse in their sensitivities to psychostimulant drugs. BMC Pharmacol 6: 6, 2006.

HOLUBOVA A, SEVCIKOVA M, MACUCHOVA E, HREBICKOVA I, POMETLOVA M, SLAMBEROVA R: Effects of perinatal stress and drug abuse on maternal behavior and sensorimotor development of affected progeny. Physiol Res 66 (Suppl 4): S481-S491, 2017. https://doi.org/10.33549/physiolres.933800

HREBICKOVA I, SEVCIKOVA M, NOHEJLOVA K, SLAMBEROVA R: Does effect from developmental methamphetamine exposure on spatial learning and memory depend on stage of neuroontogeny? Physiol Res 65 (Suppl 5): S577-S589, 2016. https://doi.org/10.33549/physiolres.933534

JOHNSON MS, MOORE RL, BROWN DA: Sex differences in myocardial infarct size are abolished by sarcolemmal KATP channel blockade in rat. Am J Physiol Heart Circ Physiol 290: H2644-H2647, 2006. https://doi.org/10.1152/ajpheart.01291.2005

LAVRETSKY H, KIM MD, KUMAR A, REYNOLDS CF 3RD: Combined treatment with methylphenidate and citalopram for accelerated response in the elderly: an open trial. J Clin Psychiatry 64: 1410-1414, 2003. https://doi.org/10.4088/jcp.v64n1202

LAVRETSKY H, REINLIEB M, ST CYR N, SIDDARTH P, ERCOLI LM, SENTURK D: Citalopram, methylphenidate, or their combination in geriatric depression: a randomized, double-blind, placebo-controlled trial. Am J Psychiatry 172: 561-569, 2015. https://doi.org/10.1176/appi.ajp.2014.14070889

LEUNG KP, QU YH, QIAO DF, XIE WB, LI DR, XU JT, WANG HJ, YUE X: Critical role of insulinlike growth factor binding protein5 in methamphetamineinduced apoptosis in cardiomyocytes. Mol Med Rep 10: 2306-2312, 2014. https://doi.org/10.3892/mmr.2014.2572

LIU H, FENG W, ZHANG D: Association of ADHD medications with the risk of cardiovascular diseases: a metaanalysis. Eur Child Adolesc Psychiatry 28: 1283-1293, 2019. https://doi.org/10.1007/s00787-018-1217-x

LUETHI D, KAESER PJ, BRANDT SD, KRAHENBUHL S, HOENER MC, LIECHTI ME: Pharmacological profile of methylphenidate-based designer drugs. Neuropharmacology 134: 133-140, 2018. https://doi.org/10.1016/j.neuropharm.2017.08.020

MA Y, CHENG WT, WU S, WONG TM: Oestrogen confers cardioprotection by suppressing Ca2+/calmodulindependent protein kinase II. Br J Pharmacol 157: 705-715, 2009. https://doi.org/10.1111/j.14765381.2009.00212.x

MAENO Y, IWASA M, INOUE H, KOYAMA H, MATOBA R, NAGAO M: Direct effects of methamphetamine on hypertrophy and microtubules in cultured adult rat ventricular myocytes. Forensic Sci Int 113: 239-243, 2000. https://doi.org/10.1016/s0379-0738(00)00216-4 
MILEROVA M, DRAHOTA Z, CHYTILOVA A, TAUCHMANNOVA K, HOUSTEK J, OSTADAL B: Sex difference in the sensitivity of cardiac mitochondrial permeability transition pore to calcium load. Mol Cell Biochem 412: 147-154, 2016. https://doi.org/10.1007/s11010-015-2619-4

MONTAGNINI BG, SILVA LS, Dos SANTOS AH, ANSELMO-FRANCI JA, FERNANDES GS, MESQUITA SDEF, GERARDIN DC: Effects of repeated administration of methylphenidate on reproductive parameters in male rats. Physiol Behav 133: 122-129, 2014. https://doi.org/10.1016/j.physbeh.2014.05.016

MUNK K, GORMSEN L, KIM WY, ANDERSEN NH: Cardiac arrest following a myocardial infarction in a child treated with methylphenidate. Case Rep Pediatr 2015: 905097, 2015. https://doi.org/10.1155/2015/905097

PADALA PR, PADALA KP, LENSING SY, RAMIREZ D, MONGA V, BOPP MM, ROBERSON PK, DENNIS RA, PETTY F, SULLIVAN DH, BURKE WJ: Methylphenidate for apathy in community-dwelling older veterans with mild Alzheimer's disease: A double-blind, randomized, placebo-controlled trial. Am J Psychiatry 175: 159-168, 2018. https://doi.org/10.1176/appi.ajp.2017.17030316

PATEL K, ABDOOL PS, RAJJI TK, MULSANT BH: Pharmacotherapy of major depression in late life: what is the role of new agents? Expert Opin Pharmacother 18: 599-609, 2017. https://doi.org/10.1080/14656566.2017.1308484

PAULY V, FRAUGER E, LEPELLEY M, MALLARET M, BOUCHERIE Q, MICALLEF J: Patterns and profiles of methylphenidate use both in children and adults. Br J Clin Pharmacol 84: 1215-1227, 2018. https://doi.org/10.1111/bcp.13544

PIPER BJ, OGDEN CL, SIMOYAN OM, CHUNG DY, CAGGIANO JF, NICHOLS SD, MCCALL KL: Trends in use of prescription stimulants in the United States and Territories, 2006 to 2016. PLoS One 13: e0206100, 2018. https://doi.org/10.1371/journal.pone.0206100

RORABAUGH B, SEELEY S, EVANS M, MARENGO C, D'SOUZA M: Differential behavioral effects of nicotine in adult male and female rats with a history of prenatal methamphetamine exposure. Neurosci Lett 651: 116-122, 2017a. https://doi.org/10.1016/j.neulet.2017.05.002

RORABAUGH BR, CHAKRAVARTI B, MABE NW, SEELEY SL, BUI AD, YANG J, WATTS SW, NEUBIG RR, FISHER RA: Regulator of G protein signaling 6 protects the heart from ischemic injury. J Pharmacol Exp Ther 360: 409-416, 2017b. https://doi.org/10.1124/jpet.116.238345

RORABAUGH BR, SEELEY SL, BUI AD, SPRAGUE L, D'SOUZA MS: Prenatal methamphetamine differentially alters myocardial sensitivity to ischemic injury in male and female adult hearts. Am J Physiol Heart Circ Physiol 310: H516-H523, 2016. https://doi.org/10.1152/ajpheart.00642.2015

RORABAUGH BR, SEELEY SL, STOOPS TS, D'SOUZA MS: Repeated exposure to methamphetamine induces sexdependent hypersensitivity to ischemic injury in the adult rat heart. PLoS One 12: e0179129, 2017c. https://doi.org/10.1371/journal.pone.0179129

ROSENBERG PB, LANCTOT KL, DRYE LT, HERRMANN N, SCHERER RW, BACHMAN DL, MINTZER JE, ADMET INVESTIGATORS: Safety and efficacy of methylphenidate for apathy in Alzheimer's disease: a randomized, placebo-controlled trial. J Clin Psychiatry 74: 810-816, 2013. https://doi.org/10.4088/jep.12m08099

SCHULTZ JE, HSU AK, BARBIERI JT, LI PL, GROSS GJ: Pertussis toxin abolishes the cardioprotective effect of ischemic preconditioning in intact rat heart. Am J Physiol 275: H495-H500, 1998. https://doi.org/10.1152/ajpheart.1998.275.2.h495

SHAO Q, FALLICA J, CASIN KM, MURPHY E, STEENBERGEN C, KOHR MJ: Characterization of the sexdependent myocardial S-nitrosothiol proteome. Am J Physiol Heart Circ Physiol 310: H505-H515, 2016. https://doi.org/10.1152/ajpheart.00681.2015

SHIN JY, ROUGHEAD EE, PARK BJ, PRATT NL: Cardiovascular safety of methylphenidate among children and young people with attention-deficit/hyperactivity disorder (ADHD): nationwide self controlled case series study. BMJ 353: i2550, 2016. https://doi.org/10.1136/bmj.i2550

SLAMBEROVA R: Review of long-term consequences of maternal methamphetamine exposure. Physiol Res 68 (Suppl 3): S219-S231, 2019. https://doi.org/10.33549/physiolres.934360 
SUGIMOTO K, OKAMURA K, TANAKA H, TAKASHIMA S, OCHI H, YAMAMOTO T, MATOBA R: Methamphetamine directly accelerates beating rate in cardiomyocytes by increasing $\mathrm{Ca}(2+)$ entry via L-type $\mathrm{Ca}(2+)$ channel. Biochem Biophys Res Commun 390: 1214-1220, 2009. https://doi.org/10.1016/j.bbrc.2009.10.124

THOMPSON J, THOMPSON JR: Acute myocardial infarction related to methylphenidate for adult attention deficit disorder. J Emerg Med 38: 18-21, 2010. https://doi.org/10.1016/j.jemermed.2007.06.021

WANG Y, WANG Q, ZHAO Y, GONG D, WANG D, LI C, ZHAO H: Protective effects of estrogen against reperfusion arrhythmias following severe myocardial ischemia in rats. Circ J 74: 634-643, 2010. https://doi.org/10.1253/circj.cj-09-0223

WONG YN, KING SP, LAUGHTON WB, MCCORMICK GC, GREBOW PE: Single-dose pharmacokinetics of modafinil and methylphenidate given alone or in combination in healthy male volunteers. J Clin Pharmacol 38: 276-282, 1998. https://doi.org/10.1002/j.1552-4604.1998.tb04425.x

ZULOAGA DG, WANG J, WEBER S, MARK GP, MURPHY SJ, RABER J: Chronic methamphetamine exposure prior to middle cerebral artery occlusion increases infarct volume and worsens cognitive injury in Male mice. Metab Brain Dis 31: 975-981, 2016. https://doi.org/10.1007/s11011-016-9808-Z 